\title{
Impedance Measurements for Electroless Nickel Plating Process
}

\author{
S. Karthikeyan, ${ }^{\text {a), }}$ K.N. Srinivasan, ${ }^{\text {b) }}$ T. Vasudevan, ${ }^{\text {c) }}$ S. John ${ }^{\text {b) }}$ \\ a) Department of Chemistry, National Engineering College, Kovilpatti-628503, India \\ ${ }^{b)}$ Central Electrochemical Research Institute, Karaikudi-630 006, India \\ c) Department of Industrial Chemistry, Alagappa University, Karaikudi-630 003, India
}

Received 29 April 2005; accepted in revised form 6 April 2006

\begin{abstract}
Electroless nickel (EN) process is the controlled auto catalytic reduction of nickel ions using suitable reducing agent such as sodium hypophosphite on certain catalytic surfaces, which results in the production of sound, coherent coatings for a number of applications. Frequently the rate of deposition of EN with hypophosphite as reducing agent is below 20 microns per hour. Hence the deposition of the electroless nickel with hypophosphite solution in the presence of small concentration of thiourea and its derivatives as accelerators is investigated. The mechanism of accelerated deposition is studied by impedance measurements. The performance of various additives during the plating process is being evaluated by increased Constant Phase Element (CPE) and decreased charge transfer resistance values. A model is proposed for the adsorptive behavior of additives.
\end{abstract}

Keywords: electroless nickel, impedance studies, accelerators, thiourea and its derivatives.

\section{Introduction}

In the recent years there has been considerable interest in the electroless nickel plating due to its extensive use in electronics, automobiles, aerospace and other industries. Electroless nickel plating is a controlled autocatalytic reduction of nickel ions using suitable reducing agent such as sodium hypophosphite. The process results into deposition of uniform adherent coating on some catalytic surfaces. The rate of deposition of electroless nickel with hypophosphite solutions is normally limited to below $20 \mu \mathrm{m}$ per hour. Attempts are in progress to increase the deposition rate for engineering applications. It has been established that thiourea and other sulphur containing compounds like

\footnotetext{
* Corresponding author. E-mail address: drskarthikeyanphd@gmail.com
} 
thiocyanate increase the rate of deposition when present in small concentrations [1-6]. In the present studies attempts are being made to understand the acceleration mechanism using thiourea and its derivatives as accelerators through impedance measurements.

In these studies two parameters are of great interest:

a) the decreased charge transfer resistance values;

b) the increased Constant Phase Element (CPE) values.

\section{Experimental procedure}

Copper specimens of $99.99 \%$ purity of size $2 \times 5 \times 0.2 \mathrm{~cm}$ were pretreated and activated in palladium chloride solution. The electrolytic solution used and the list of thiourea and its derivatives used as accelerators were reported in our earlier paper [6]. An EG\&G Princeton Applied Research - Model 6310 impedance analyzer was used for this measurement. The real part ( $\left.Z^{\prime}\right)$ and the imaginary part ( $Z$ '') of the cell impedance were measured for various frequencies $(100 \mathrm{kHz}$ to $10 \mathrm{mHZ})$ using the frequency response analyzer. The impedance measurements were carried out both in the presence and absence of the additives for their optimum concentrations at room temperature. In this measurement $1 \mathrm{~cm}^{2}$ area of electrolessly deposited metal surface was used as a working electrode, 4 $\mathrm{cm}^{2}$ area of platinum electrode and saturated calomel electrode were used as counter and reference electrodes. The AC perturbation voltage was $10 \mathrm{mV}$ over the rest potentials and the rest potential was $-400 \mathrm{mV}$.

From the Nyquist plot, the charge transfer resistance and Constant Phase Element (CPE) values were calculated.

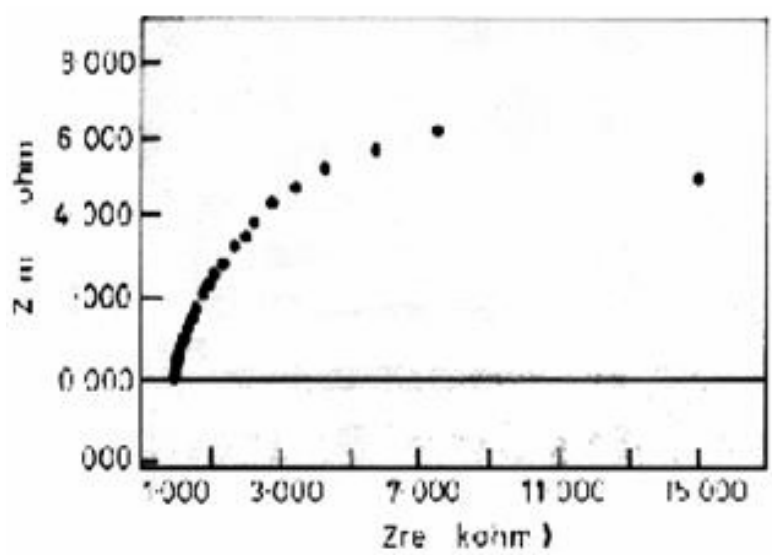

Figure 1. Nyquist diagram of EN system in the absence of accelerators. 


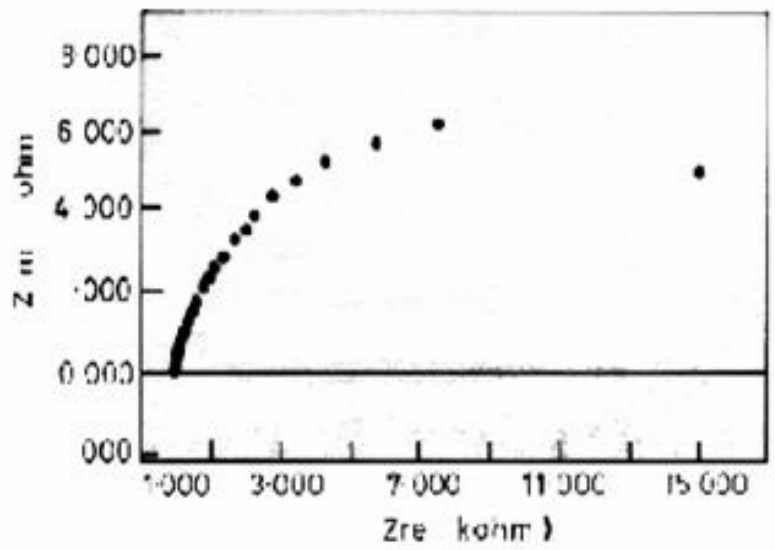

Figure 2. Nyquist diagram of EN in the system containing $3 \times 10^{-3} \mathrm{mM}$ TU.

\section{Results and discussion}

The A.C. impedance spectra obtained during the electroless nickel deposition and simultaneous oxidation of the hypophosphite in the presence and absence of the accelerators in their optimum concentration at room temperature are given in Fig. 1-10 and Table 1.

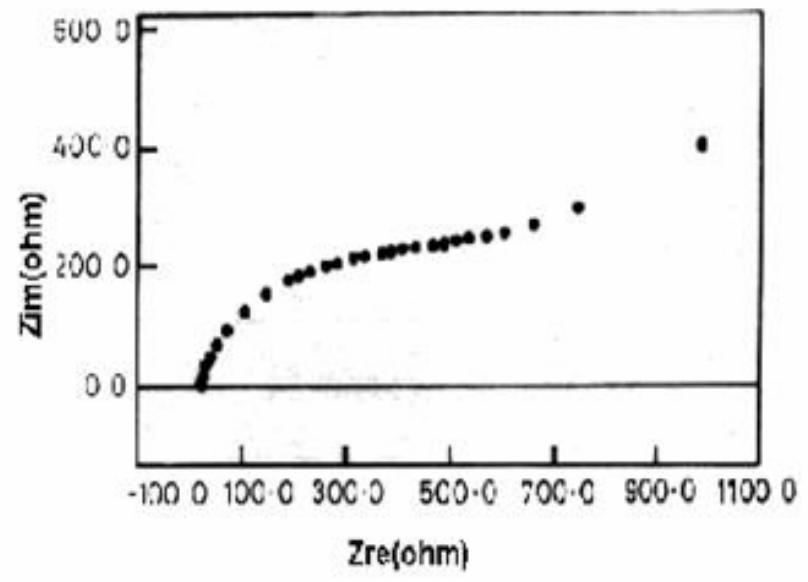

Figure 3. Nyquist diagram of EN system containing $1.11 \times 10^{-3} \mathrm{mM}$ Me TU. 


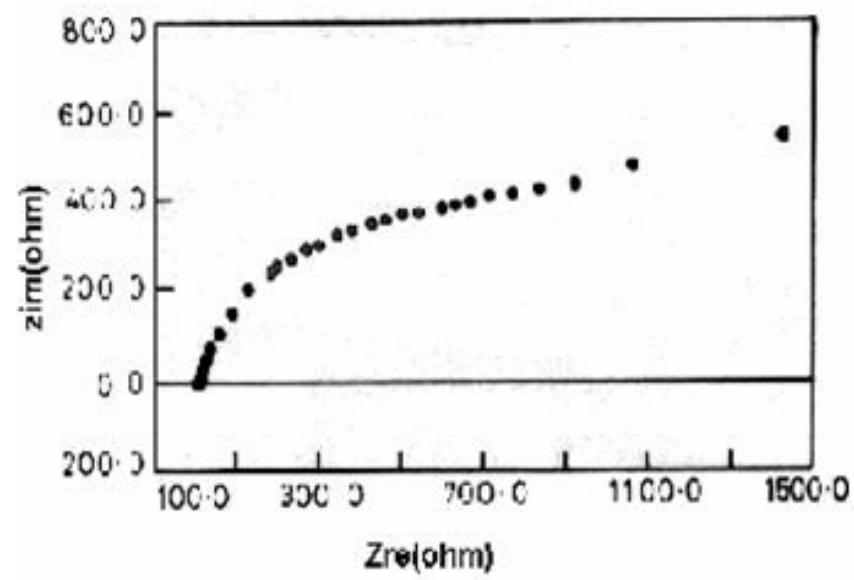

Figure 4. Nyquist diagram of EN system containing $2.94 \times 10^{-3} \mathrm{mM} \mathrm{Et}-\mathrm{TU}$.

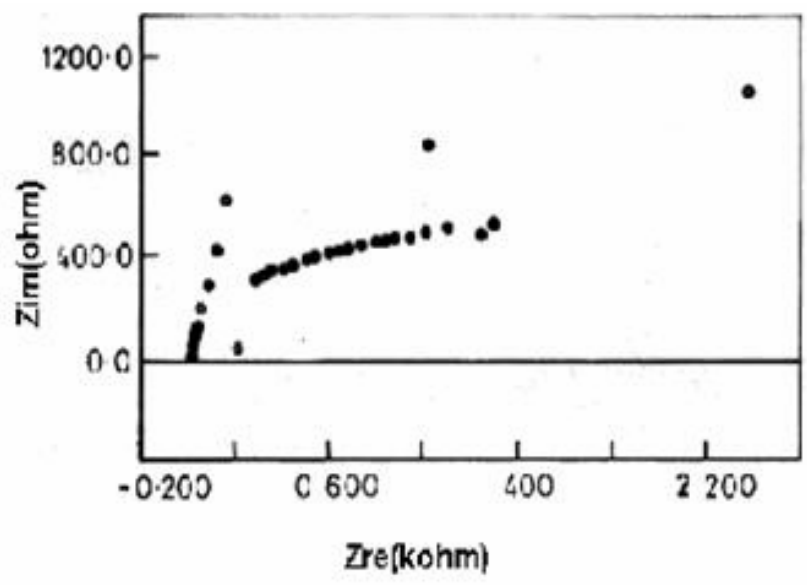

Figure 5. Nyquist diagram of EN system containing $4.3 \times 10^{-3} \mathrm{mM}$ ALLTU.

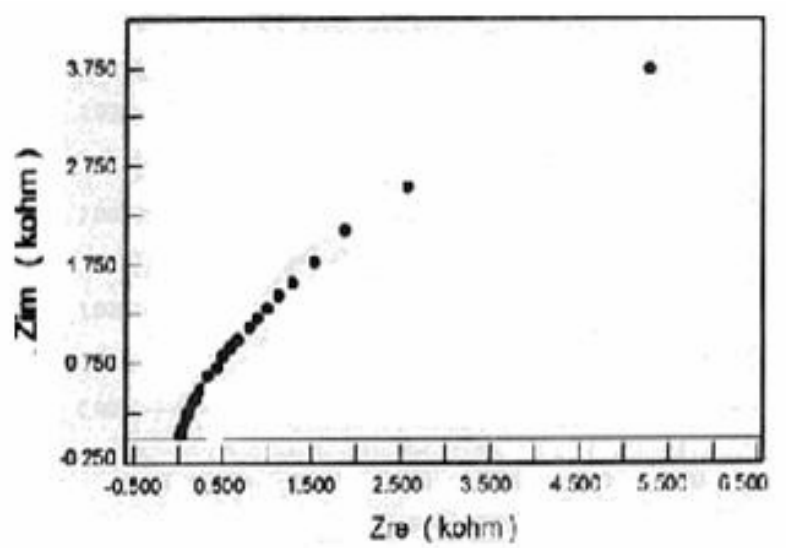

Figure 6. Nyquist diagram of EN system containing $3.39 \times 10^{-3} \mathrm{mM}$ ACTU.

In this experiment the A.C. voltage is superimposed on the rest potential on electrolessly deposited Ni-P alloy electrode immersed in the electrolytic solution. The rest potential or the mixed potential is that one at which two different electrochemical reactions occur simultaneously on the Ni-P surface in the metal / 
solution interface. Thus the overall reaction in the electroless nickel plating system is as follows:

$$
\mathrm{Ni}^{2+}+\mathrm{H}_{2} \mathrm{PO}_{2}^{-}+\mathrm{H}_{2} \mathrm{O} \rightarrow \mathrm{Ni}+\mathrm{H}_{2} \mathrm{PO}_{3}^{-}+2 \mathrm{H}^{+}
$$

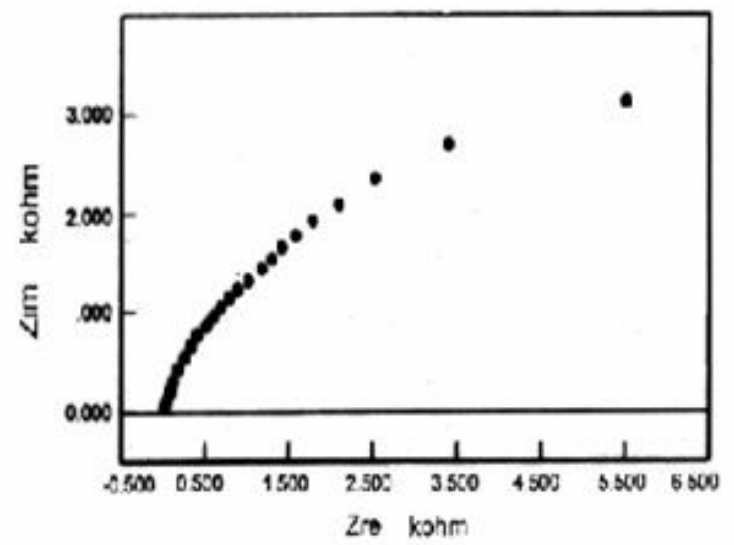

Figure 7. Nyquist diagram of EN system containing $0.9 \times 10^{-3} \mathrm{mM}$ p-TLTU.

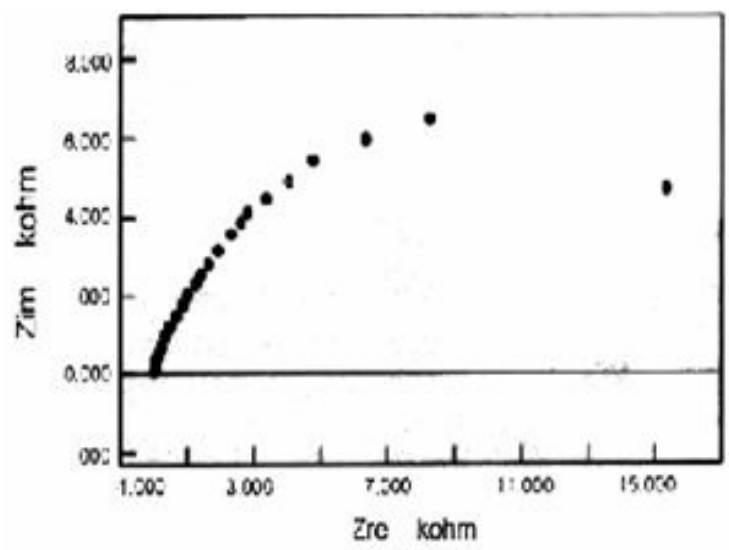

Figure 8. Nyquist diagram of EN system containing $3.07 \times 10^{-3} \mathrm{mM}$ DphTU.

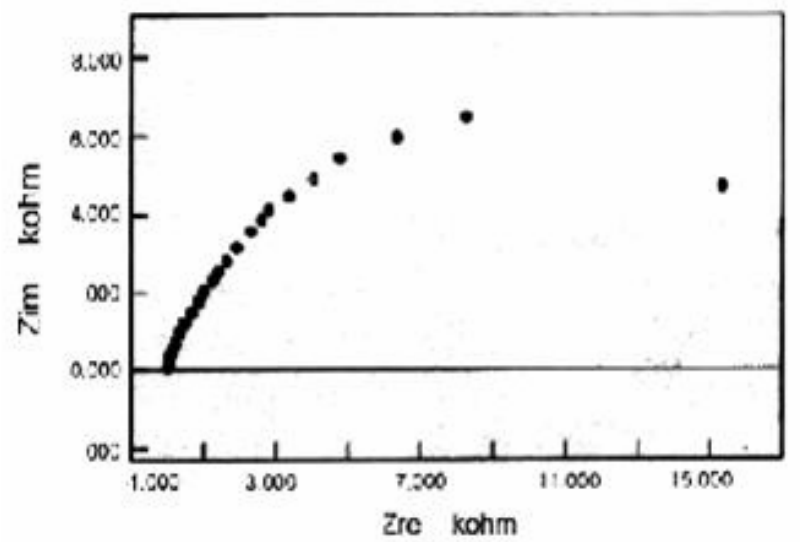

Figure 9. Nyquist diagram of EN system containing $0.88 \times 10^{-3} \mathrm{mM}$ p-TSCD. 


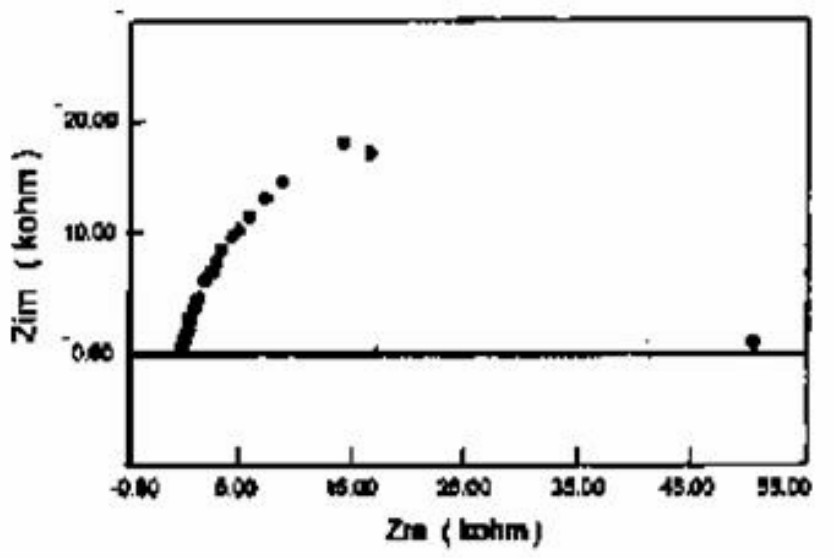

Figure 10. Nyquist diagram of EN system containing $2.66 \times 10^{-3} \mathrm{mM}$ TMA.

Using the Nyquist plots the charge transfer resistance values of the above reaction are calculated as the $X$ intercept of the semicircle where the $\mathrm{X}$-axis represents the real part of the impedance. Perfect semicircles are encountered, in case where the electrochemical reaction of interest is under charge transfer control. Where the reactions are partially under charge transfer and mass transport control there is a drag noted in the semicircular plot. When the reaction is under diffusion control a rising portion is noted in the low frequency end of the plot. Also any looping at the tail end of the plot is attributed to the contribution of the Warburg impedance.

Table 1. Values of charge transfer resistance and double layer capacitance obtained from the impedance measurements in the presence and absence of all additives.

\begin{tabular}{|l|c|c|}
\hline \multicolumn{1}{|c|}{ Accelerator } & $\begin{array}{c}\mathbf{R}_{\mathbf{t}} / \\
\text { K.ohm.cm }\end{array}$ & $\begin{array}{c}\mathbf{C P E} /{ }^{\mathbf{2}} \\
\boldsymbol{\mu} \mathbf{F . c m}\end{array}$ \\
\hline No accelerator & 15.00 & 39 \\
Methyl thiourea & 1.10 & 977 \\
N,N'-Ethylene thiourea & 1.50 & 790 \\
Allyl thiourea & 2.50 & 500 \\
Acetyl thiourea & 6.50 & 138 \\
p-Tolyl thiourea & 6.90 & 125 \\
Thio semicarbazide & 12.99 & 63 \\
Thiourea & 13.99 & 41 \\
Diphenyl thiourea & 14.20 & 40 \\
Thio malic acid & 35.00 & 10 \\
\hline
\end{tabular}

In most of the impedance plots the semicircles are not complete, particularly at the low frequency end, and they are to be estimated by extrapolation of a best fitted half circle for the experimental values. Such type of behaviour has been reported for the corrosion of stainless steel in $1.8 \mathrm{M}$ aerated $\mathrm{H}_{2} \mathrm{SO}_{4}$ and it is accounted as due to the slow corrosion process [7-8].

In the present case the situation is similar as it corresponds to a highly resistive condition for the above charge transfer reactions reflected in their high $\mathrm{R}_{\mathrm{t}}$ values. 
Impedance studies have been adapted to understand the behaviour of thiourea function as accelerator in EN electrolytic solution [9]. The decreased $R_{t}$ value is claimed to reflect on the accelerating effect on the additives during plating process. Further the influence of some of the organic additives such as 2,2'dipyridyl, pyridine and 1,10-phenanthrolene on electroless deposition of copper has been reported through impedance studies [10]. The $\mathrm{R}_{t}$ values have decreased compared with the bath devoid of the accelerator for all the additives except for TMA indicating the same trend in performance as in other studies.

The performance of the compounds as accelerators is mainly controlled through their adsorption on the metal surface. A suitable model (Fig. 11) is proposed to illustrate the effect of the accelerators in the electroless nickel deposition based on earlier works $[7,2]$. The importance of sulphur containing organic compounds as accelerators lies in their ability to get adsorbed through the highly polar sulphur atom. Studies with the thio compounds predict the adsorption to occur through the sulphur atom mainly even if nitrogen atom is also present in the molecule. Adsorption through sulphur atom can be predicted from the "Principle of Hard and Soft Acids and Bases" [4], the metal being the "soft acid" and the sulphur compounds are "soft bases". Soft pairs have the strong tendency to interact, which is evident from the general rule of acid-base interaction [11]. The sulphur atom of the molecule being the most polarisable and lowest electronegative one, can easily establish adsorption on the catalytic surface of the metal. In the tetrahedral hypophosphite ion, the higher electronegativity of oxygen atom causes the phosphorus to be positively charged. A reactive intermediate formation is envisaged through a chemical interaction between the $\mathrm{P}^{\delta+}$ of the $\mathrm{H}_{2} \mathrm{PO}_{2}^{-}$ion and $\mathrm{S}^{\delta-}$ of the accelerator, which probably accounts for the weakening of the $\mathrm{P}-\mathrm{H}$ bond in $\mathrm{H}_{2} \mathrm{PO}_{2}^{-}$. This results in the easy oxidation of the hypophosphite. The free radical formed through cleavage of $\mathrm{P}-\mathrm{H}$ bond of $\mathrm{H}_{2} \mathrm{PO}_{2}{ }^{-}$ combines with $\mathrm{OH}^{-}$of the EN solution and produces the $\mathrm{H}_{2} \mathrm{PO}_{3}{ }^{-}$ions. The reduction in $\mathrm{pH}$ during $\mathrm{EN}$ is quite understandable with evolution of hydrogen. Further following the cleavage of $\mathrm{P}-\mathrm{H}$ bond the electron on the $\mathrm{P}$ atom can be easily transmitted to the metal surface through the polar sulphur atom of the accelerator molecules. This results in the catalytic activity of the metal surface to be enhanced for the accelerated metal ion reduction. Also $\mathrm{H}_{2} \mathrm{PO}_{2}{ }^{-}$ion can be further reduced elemental phosphorus which can be codeposited with nickel resulting in the formation of $\mathrm{Ni}-\mathrm{P}$ alloy.

These sequences are pictured below: 

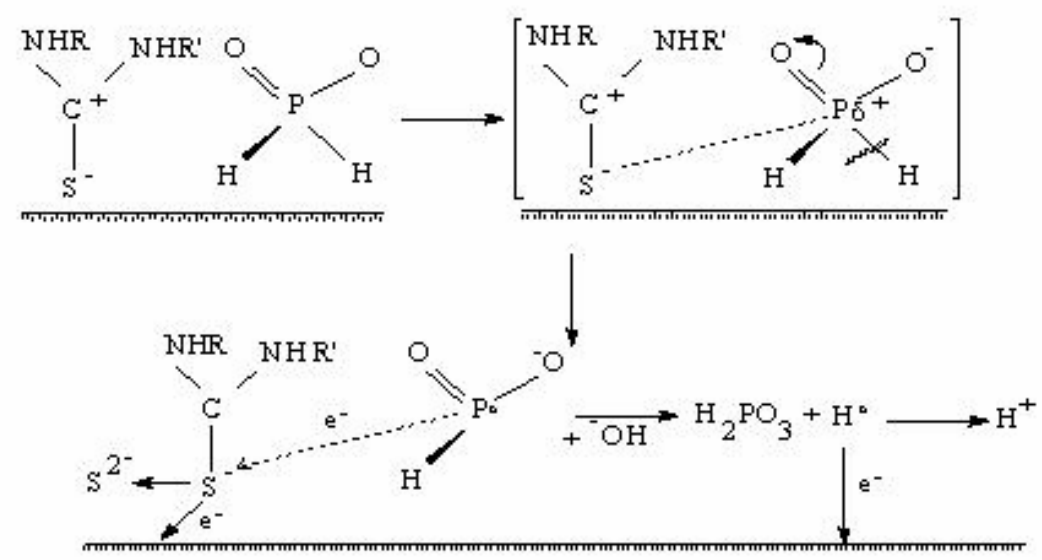

Where $\mathrm{R}=-\mathrm{H},-\mathrm{CH}_{3},-\mathrm{CH}_{2} \mathrm{CH}_{2},-\mathrm{CH}_{2} \mathrm{CH}=\mathrm{CH}_{2},-\mathrm{CH}_{3} \mathrm{CO},-\mathrm{C}_{6} \mathrm{H}_{5}$

$\mathrm{R}^{\prime}=-\mathrm{H},-\mathrm{CH}_{3}-\mathrm{C}_{6} \mathrm{H}_{4},-\mathrm{C}_{6} \mathrm{H}_{5}$

Figure 11. A proposed model for the accelerators in electroless nickel plating process.

The above model and mechanism of hydrogen permeation in the presence of the accelerators suggest the possible incorporation of $\mathrm{S}^{2-}$ in the deposit. The XPS analysis carried out with electroless nickel deposition in the presence of thioglycolic acid and cysteine $[2,4]$ as accelerators suggests the presence of trace amount of accelerator on the surface and $\mathrm{S}^{2-}$ in the inner layer of the deposit.

The A.C. impedance spectra obtained during the electroless plating are characterized by distortions and / or discontinuities unlike the ones obtained for $\mathrm{Ni}^{2+}$ reduction in the catholyte solution. This situation is attributed to the surface inhomogeneties [3,7]. The action of thiourea and its derivatives in accelerating nickel deposition kinetics is the promotion of electron exchange reactions due to increased $\mathrm{Ni}^{2+}$ activities, resulting from the adsorption of the compounds on the electrode surface. It was reported [5] that certain organic compounds, due to moments or distortion moments, induce some electric field which results in the tendency for adsorption of the molecules on the metal surface and promotes electron exchange reactions thereon by penetrating the dissolving barrier films on the electrode surface. Such anions substantially change both anodic and cathodic over potential and catalyse the electrochemical reactions. Thiourea and its derivatives (except TMA) may fall in to this category.

\section{Conclusion}

Following is the performance grading of the different accelerators namely thiourea, its derivatives and TSCD and TMA .

$$
\begin{gathered}
\text { METU }>\text { N,N'-EtTU }>\text { ALLTU }>\text { ACTU }>\text { p-TLTU }>\text { TU }>\text { DPhTU } \\
\text { TSCD }>\text { TMA }
\end{gathered}
$$

A suitable model has been proposed to illustrate the effect of the accelerators in the electroless nickel deposition. 


\section{Acknowledgement}

One of the authors, S. K., would like to express his sincere thanks to the Principal and Management of National Engineering College, K.R. Nagar, Kovilpatti 628503, India, for their constant encouragement and support.

\section{References}

1. K.P. Han and J.L. Fang, Stabilization effect of electroless nickel plating by thiourea, Metal Finishing 2 (1997) 73.

2. J.L. Fang, Y. Lu and K.P. Han, Acceleration mechanism of thioglycolic acid for electroless nickel deposition, Plating and Surface Finishing 9 (1997) 91.

3. A. Oni, The mode of action of thiourea in electroless nickel plating, Trans. IMF 66 (1988) 47.

4. K.P. Han and J.L. Fang, Effect of cysteine on the kinetics of electroless nickel deposition, J. Appl. Electrochem. 26 (1996) 1273.

5. K.N. Srinivasan and I. Venkatakrishna, Effect of derivatives of thiourea on hydrogen permeation during zinc plating, Trans. SAEST 24-2 (1989) 205.

6. K.N. Srinivasan, S. Karthikeyan, T. Vasudevan S. and John, Hydrogen permeation measurements for electroless nickel plating process, Electroplating and Finishing 23-1 (2004) 1-6.

7. S. Karthikeyan, An investigation on the electroless nickel plating process and its Composites, Ph.D. Thesis, Alagappa University, India Oct 2001.

$8 \mathrm{Gu}$ and Hough, Diffusion of hydrogen in metals III study on the effect of thiourea and its derivatives on hydrogen penetration rate in steel in hydrochloric acid, Chemical Abstracts 98, 38540n.

9. K.N. Srinivasan, S. Karthikeyan, T. Vasudevan and S. John, Hydrogen permeation measurements for electroless nickel plating process, Electroplating and Finishing Feb(2004), issue China.

10. T. Minani and S.M. Mayanna, Electroless nickel plating from an acidic tartrate bath, Plating and Surface Finishing 2 (1993) 66.

11. K.N. Srinivasan, Studies on the influence of organic additives in electroplating bath with special reference to zinc plating bath, Ph.D. Thesis, Madurai Kamraj University, India, Nov. 1988. 